\title{
RANCIDITY DEVELOPMENT DURING THE CHILLED STORAGE OF FARMED COHO SALMON (Oncorhynchus kisutch)
}

Santiago P. Aubourg ${ }^{\mathrm{a},}$, Julia Vinagre $^{\mathrm{b}}$, Alicia Rodríguez ${ }^{\mathrm{b}}$, Vanesa Losada $^{\mathrm{a}}$, M. Angélica Larraín ${ }^{b}$, Vilma Quitral ${ }^{\mathrm{b}}$, Julio Gómez ${ }^{\mathrm{c}}$, Liliana Maier ${ }^{\mathrm{d}}$ and Emma Wittig ${ }^{\mathrm{b}}$

${ }^{a}$ Department of Seafood Chemistry, Institute for Marine Research (IIM-CSIC), Vigo (Spain).

${ }^{b}$ Department of Food Science and Chemical Technology. University of Chile, Santiago (Chile).

${ }^{c}$ Health Environment Service. Santiago (Chile).

${ }^{d}$ Department of Microbiology. University of Santo Tomás de Aquino. Santiago (Chile).

* Correspondent: FAX: +34986292762; e-mail: saubourg@iim.csic.es 


\section{SUMMARY}

Coho salmon (Oncorhynchus kisutch) is a fatty fish species whose farming production has greatly increased in recent years. Lipid damage produced during Coho salmon chilled storage was studied up to 24 days. Lipid hydrolysis (free fatty acids, FFA) and oxidation (conjugated dienes; peroxide value, PV; thiobarbituric acid index, TBA-i; fluorescent compounds formation, FR; browning development) were determined and compared to lipid composition (polyene index, PI; astaxanthin, AX) changes and sensory assessment (rancid odour development). Most lipid damage indices developed slowly during storage; thus, values obtained for FFA, PV, TBA-i and FR were in all cases under $1.5 \mathrm{~g} / 100 \mathrm{~g}, 4.0 \mathrm{meq}$ oxygen $/ \mathrm{kg}$ lipid, $0.40 \mathrm{mg}$ malondialdehyde $/ \mathrm{kg}$ muscle and 0.40 , respectively. Odour assessment showed a significant $(\mathrm{p}<0.05)$ rancid development at day 10, when compared to starting fish material; then, non acceptable values were obtained at days 19 and 24 . The PI analysis showed little differences during the storage time, being the lowest mean value at day 19. AX analysis indicated a relatively high content in the white muscle, that was maintained till the end experiment. A low oxidation development is concluded for Coho salmon lipids when compared to other fatty fish species under the same chilling conditions. AX was found to contribute to oxidation stability of Coho salmon lipids, due to its free radical scavenger properties.

Running Title: Rancidity in chilled Coho salmon

$\underline{\text { Keywords: }}$ Coho salmon, aquaculture, chilling, rancidity, odour, astaxanthin, quality 


\section{INTRODUCTION}

Marine foods have attracted a great attention from consumer as a source of high amounts of important nutritional components that could lead to a positive role on human health and nutrition $[1,2]$. However, in recent years the fishing sector has suffered from dwindling stocks of traditional species as a result of dramatic changes in their availability. This has prompted fish technologists and the fish trade to pay more attention to aquaculture techniques as a source of fish and other seafood products [3, 4].

Among cultivated fish, Coho salmon (Oncorhynchus kisutch), also called silver salmon, has received a great attention because of its increasing production in Chile, where production values round 76,000, 93,000 and 137,000 metric tonnes were attained for years 1999, 2000 and 2001, respectively [5]. Thus, most research concerning aquaculture production has been carried out for reproductive parameters and genetic differences $[6,7]$. However, previous composition or technological research related to this salmon species only concerns the cholesterol content [8] and the fatty acid distribution in fresh [9], frozen [10] and canned [8] products.

Wild and farmed fish species are known to deteriorate rapidly after death due to the action of different mechanisms, such as microbiological development, endogenous enzyme activity, nonenzymatic lipid oxidation, and browning [11]. Marine lipids comprise by highly unsaturated fatty acids that are known to be very prone to lipid oxidation $[12,13]$. During chilled storage of fatty fish species, a strong effect of lipid damage has been detected on fish quality loss $[14,15]$ that leads to a negative effect on commercial value.

The present work concerns Coho salmon and its commercialisation as a chilled product. Lipid hydrolysis and oxidation assessments were carried out during a 24 day 
storage period. Traditional lipid damage indices (free fatty acids, conjugated dienes, peroxides, thiobarbituric acid reactive substances, fluorescent compounds formation and browning development) were compared to lipid composition (astaxanthin and polyenes) changes and sensory assessment (rancid odour development).

\section{MATERIALS AND METHODS}

\subsection{Raw material, processing, sampling and chemicals}

Farmed Coho salmon (Oncorhynchus kisutch) specimens used in this study were cultivated by EWOS Innovation Research (Colaco, Puerto Montt, Chile). The feed employed contained $40.0 \%$ protein, $28.4 \%$ fat, $16.5 \%$ carbohydrate, $1.6 \%$ crude fibre, $7.5 \%$ moisture and $6.0 \%$ ash; the fatty acid composition $(\%)$ of the diet expressed by fatty acid groups was as follows: $32.5 \%$ (saturated), 27.0 (monounsaturated) and 40.2 $\%$ (polyunsaturated). In December 2003, the fish specimens (weight range: 3.0-3.4 kg) were sacrificed by a sharp blow to the head, the gills cut, bled in a water-ice mixture, headed, gutted and kept in ice for 24 hours until they arrived at our laboratory. The fish specimens were then stored on ice in an isothermal room at $2^{\circ} \mathrm{C}$. Samples were taken for analysis on days $0,3,6,10,12,17,19$ and 24 . Five different individuals were analysed by day $(n=5)$ and studied separately to achieve the statistical analysis. Once fish specimens had been subjected to sensory analysis, the white muscle was separated and used for the different biochemical analyses.

Chemicals employed along the present work (solvents, reagents) were reagent grade (E. Merck; Darmstadt, Germany). 


\subsection{Water and lipid contents}

Water content was determined by the difference between the weight of fresh homogenized muscle (1-2 g) and the weight recorded after $24 \mathrm{~h}$ at $105{ }^{\circ} \mathrm{C}$. Results are expressed as g water/100 g muscle. Lipids were extracted by the Bligh and Dyer [16] method. Quantification results are expressed as g lipid/100 g wet muscle.

\subsection{Lipid damage analysis}

Free fatty acid (FFA) content was determined by the Lowry and Tinsley [17] method based on complex formation with cupric acetate-pyridine. Results are expressed as g FFA/100 g lipids.

Conjugated diene (CD) formation was measured at $233 \mathrm{~nm}$ [18]. Results are expressed according to the following formula $\mathrm{CD}=\mathrm{B} \times \mathrm{V} / \mathrm{w}$, where $\mathrm{B}$ is the absorbance reading at $233 \mathrm{~nm}, \mathrm{~V}$ is the volume $(\mathrm{ml})$ and $\mathrm{w}$ is the mass $(\mathrm{mg})$ of the lipid extract measured.

The peroxide value (PV), expressed as meq oxygen/kg lipid, was determined by the ferric thiocyanate method [19].

The thiobarbituric acid index (TBA-i) was determined according to Vyncke [20]. Results are expressed as mg malondialdehyde $/ \mathrm{kg}$ fish sample.

Formation of fluorescent compounds was determined with a Perkin Elmer LS 3B fluorometer by measurements at $393 / 463 \mathrm{~nm}$ and $327 / 415 \mathrm{~nm}$, as previously described $[21,22]$. The relative fluorescence $(R F)$ was calculated as follows: $R F=F / F_{\text {st }}$, where $F$ is the fluorescence measured at each excitation/emission maximum, and $F_{\text {st }}$ is the fluorescence intensity of a quinine sulphate solution $\left(1 \mu \mathrm{g} / \mathrm{ml}\right.$ in $\left.0.05 \mathrm{M} \mathrm{H}_{2} \mathrm{SO}_{4}\right)$ at the corresponding wavelength. The fluorescence ratio (FR) was calculated as the ratio 
between the two $\mathrm{RF}$ values: $\mathrm{FR}=\mathrm{RF}_{393 / 463 \mathrm{~nm}} / \mathrm{RF}_{327 / 415 \mathrm{~nm}}$. The $\mathrm{FR}$ value was determined in the aqueous phase resulting from the lipid extraction [16].

Browning development was measured from the lipid extract at $450 \mathrm{~nm}$ and 400 $\mathrm{nm}$. The $450 \mathrm{~nm} / 400 \mathrm{~nm}$ absorbance ratio (browning ratio, BR) was studied according to Hassan et al. [23].

\subsection{Fatty acid analysis and polyene index}

Lipid extracts were converted into fatty acid methyl esters and analysed by gas chromatography according to the method of Lepage and Roy [24]. The polyene index (PI) was calculated as the following fatty acid ratio: C 20:5 + C 22:6 / C 16:0 [25].

\subsection{Astaxanthin assessment}

Astaxanthin content was measured according to the Sheehan et al. [26] method. The presence of different astaxanthin isomers was checked. Absence of 9Z- and 13Zisomers was confirmed; only E-isomers were detected in the present salmon samples. Results are expressed as mg all-E-astaxanthin (AX)/kg fish muscle.

\subsection{Sensory analyses}

The development of rancid odour was conducted by a sensory panel consisting of ten experienced judges, according to Howgate [27]. For each sample analysis, five fish were cooked in polyethylene bags in a water bath. Rancid odour development was then evaluated on a hedonic scale with numerical scores from 0 (stage of no rancidity at all) to 10 (stage where no increase in rancidity is possible); score 5.0 was considered the borderline of fish acceptability. Scores among panellists were averaged. 


\subsection{Statistical analyses}

Data from the different biochemical and sensory analyses were subjected to oneway analysis of variance $(\mathrm{p}<0.05)$. Correlation analyses among chilled time, rancid odour and biochemical indices were studied [28].

\section{RESULTS AND DISCUSSION}

\section{$\underline{\text { 3.1. Water and lipid contents }}$}

Water content of salmon white muscle ranged between $68 \%$ and $72 \%$ and lipid matter was included in the range 4.0-6.0\%. Variations in both constituent (water and lipids) contents may be explained as a result of individual fish variation, and not arising from chilling storage time. Water content was lower than in the case of leaner fish species such as Atlantic pomfret [29], blue whiting [21] and horse mackerel [22], according to an inverse ratio between water and lipid matter [30].

\subsection{Lipid hydrolysis}

Mean values of FFA content (Figure 1) provided an increasing trend in salmon muscle during chilled storage, so that a good correlation value $\left(r^{2}=0.96 ; n=5\right)$ was obtained with time (Table 1). Compared to the raw material, a significant $(\mathrm{p}<0.05)$ increase was observed at day 17 . The final value $(1.45 \pm 0.36)$ can be considered low when compared to FFA values of fatty fish species stored under the same conditions such as sardine [31], anchovy [32] and horse mackerel [22]. Raw fish value obtained in the present experiment was smaller than in the case of leaner fish species [21, 29], according to an inverse ratio between FFA and total lipid contents [33]. 


\subsection{Lipid oxidation}

Different and complementary lipid oxidation indices were employed to evaluate the rancidity development in the present experiment.

The conjugated diene detection did not provide significant differences $(p>0.05)$ during the chilled time (Table 2). Diene formation and breakdown have shown to be almost the same during the storage period. This index did not show to be sensitive in the present experiment for showing quality changes with time.

A slow peroxide formation was assessed during the chilled storage (Table 2) that led to a good correlation $\left(r^{2}=0.96 ; n=5\right)$ with time (Table 1$)$. Compared to raw material, a significant increase was observed at day 6 , although higher scores than 4.0 were not obtained during the experiment. Values obtained were relatively low if we compare them to o ther fish species stored under the same chilling conditions such as sardine [31], blue whiting [21] and Atlantic pomfret [29].

No formation of thiobarbituric acid reactive substances was observed in the $0-17$ day period (Table 2). However, at days 19 and then 24, significant content increases could be observed. As a result, a good correlation with time $\left(r^{2}=0.94 ; n=5\right)$ was obtained (Table 1). Again, as in the case of the peroxide detection, a relatively low oxidation development can be concluded when compared to values concerning other fish species under the same conditions $[21,31,34]$.

Compound formation as a result of interaction between oxidised lipids and nucleophilic molecules (proteins, namely) $[35,36]$ was assessed by fluorescence and browning (Table 2). Fluorescence detection provided very small mean values during the 0-19 day period. However, at the end of the experiment, a considerable increase was observed that can be related to the TBA-i increase observed in the 19-24 day period. Thus, a fair correlation value with time $\left(\mathrm{r}^{2}=0.79 ; \mathrm{n}=5\right)$ was obtained for the 
fluorescence detection (Table 1). As in the case of PV and TBA-i assessments, relatively low FR values were obtained if we compare them to previous results concerning other fish species stored under the same conditions [21, 29].

Browning detection (BR) did not provide significant $(\mathrm{p}>0.05)$ changes during the whole experiment, so that this index was not found useful for assessing quality changes in the present case.

\subsection{Fatty acid analysis and polyene index}

Fatty acid analysis of the raw material led to the following proportions (\%): 5.9

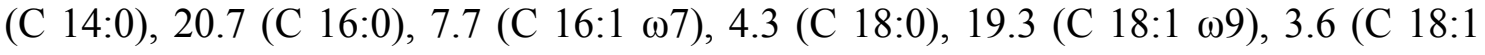

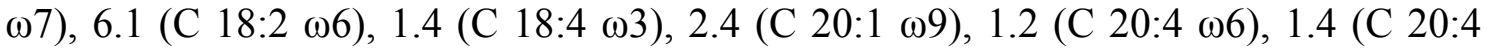

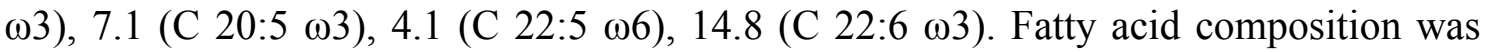
similar to that observed in canned farmed Coho salmon by Romero et al. [8] where, the

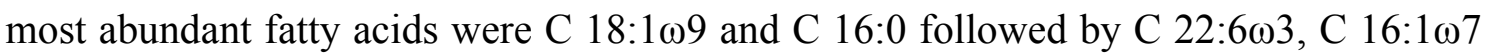
and C 20:5 $\omega 3$. However, previous research [9] on wild Coho salmon had provided some higher proportions of polyunsaturated fatty acids (C 22:6 103 and $C 20: 5 \omega 3)$ than in the present case.

Damage to polyunsaturated fatty acids during chilled storage was measured by the PI. Its analysis (Figure 2) showed little significant $(\mathrm{p}<0.05)$ differences during the storage time. Mean values provided some decreasing tendency with time, being the lowest mean value at day 19. The PI did not show to be an accurate method for assessing the quality changes during the present experiment. 


\subsection{Astaxanthin assessment}

AX content determination (Figure 3) provided slight differences during the experiment that could be explained as a result of differences from fish to fish and not as a result of the chilled storage. Raw fish value $(8.70 \pm 1.47)$ was similar to the one obtained previously for cultivated Coho salmon, but higher than the one determined for wild Coho salmon [37]. Compared to other cultivated fish species, actual raw fish value was higher than those obtained in previous research for farmed Atlantic salmon [38-40] and rainbow trout [41-43].

Previous research has shown that AX can deteriorate either due to nonenzymatic degradation, e. g. by light, heat, oxygen, or to enzymatic degradation, e. g., lipoxygenase, peroxidase [44]. In the present case, a decreasing tendency in AX content was not observed with chilled time. However, previous technological studies have shown that AX content decreases during the frozen storage of Atlantic salmon [41] and rainbow trout (Oncorhynchus mikiss) [42, 43], under vacuum packaging during chilled storage of rainbow trout [45] and as a result of post-harvesting of Atlantic salmon [39].

Carotenoids such as AX are known to act as scavengers of free radicals, so that protection against the very early stages of lipid oxidation would be favoured [43, 46]. Since a relatively high AX content in white muscle was maintained during the present experiment, low scores obtained for the PV agree with the mentioned scavenger role of the carotenoid compound.

\subsection{Rancid odour evaluation}

Odour acceptance was assessed during the chilled storage. An increase $(p<0.05)$ in rancid odour development was obtained with time (Figure 4) that led in the present case to a good correlation value $\left(r^{2}=0.96 ; n=5\right)$ (Table 1). Compared to raw material, a 
significant increase $(\mathrm{p}<0.05)$ of rancid odour was observed at day 10; then, at days 19 and 24 higher mean scores than 5.0 were obtained, so that the fish was considered not acceptable.

In previous research concerning fatty fish species, similar shelf-life times were reported for medium-sized fish species such as albacore [47] and Atlantic salmon [48], but significantly lower acceptable times were obtained for small fish species such as sardine [31] and horse mackerel [22] than in the present case.

When compared to biochemical lipid damage indices, rancid odour assessment showed a very good correlation value with lipid hydrolysis development $\left(\mathrm{FFA} ; \mathrm{r}^{2}=\right.$ $0.97 ; \mathrm{n}=5)$. FFA accumulation has been related to some extent to lack of sensory acceptability [49], being strongly interrelated with lipid oxidation development [50, 51]. Rancid odour development also showed a fair correlation value with primary $\left(\mathrm{PV} ; \mathrm{r}^{2}=\right.$ $0.87 ; \mathrm{n}=5)$ and secondary (TBA-i; $\mathrm{r}^{2}=0.84 ; \mathrm{n}=5$ ) lipid oxidation biochemical indices.

\section{CONCLUSIONS}

According to biochemical lipid damage indices (FFA, PV, TBA-i and FR), rancidity development in chilled Coho salmon was slow and values attained were low when compared to other fish species under the same storage conditions. This result was corroborated by the rancid odour development, which led to a shelf life time of 17 days.

In order to check the lipid damage development, FFA, PV, TBA-i and odour assessment were found to be accurate methods in the present experiment. In addition, the rancid odour detection showed good correlation values with some biochemical lipid damage indices (FFA, PV and TBA-i). 
A relatively high content on the endogenous antioxidant AX was observed in the white muscle of the starting fish. In spite of its known susceptibility to damage, AX content was maintained till the end of the experiment and should have contributed to lipid stability observed in the present study. Since this carotenoid is also well known as main responsible for the pink colour of salmonid fish species [52], its retention during processing should be very important to avoid quality damage, guarantee the consumer acceptance and retain the commercial value of the product.

\section{ACKNOWLEDGEMENTS}

The authors thank EWOS Innovation Research (Colaco, Puerto Montt, Chile) for kindly providing the Coho salmon fish and the Chilean-Spanish Cooperation Program (Chilean University-CSIC, Project 2003 CL 0013). Mr. Marcos Trigo is gratefully acknowledged for technical assistance. 


\section{REFERENCES}

[1] D. Illingworth, D. Ullmann: Effects of omega-3 fatty acids on risk factors for cardiovascular disease. In: Omega-3 fatty acids in health and disease. Eds. R. Lees, M. Karel, Marcel Dekker, Inc., New York (USA) and Basel (Switzerland) 1990, pp. 39-69.

[2] A. Simopoulos: Nutritional aspects of fish. In: Seafood from producer to consumer, Integrated Approach to Quality. Eds. J. Luten, T. Börrensen, J. Oehlenschläger, Elsevier Science, London (UK) 1997, pp. 589-607.

[3] FAO Inform: The state of word fisheries and aquaculture. Rome (Italy), 2000. http://www.fao.org/DOCREP/003/X8002E/X8002E00.htm.

[4] H. Josupeit, A. Lem, H. Lupin: Aquaculture Products: Quality, Safety, Marketing and Trade. In: Technical Proceedings of the Conference on Aquaculture in the Third Millennium, 2001, pp. 249-257.

[5] FAO Inform. Aquaculture production. In: Food and Agriculture Organization of the United Nations. Rome (Italy), Yearbook 2001, Vol. 92/2, 2003, pp. 70-71.

[6] F. Estay, N. Díaz, R. Neira, X. García: Reproductive performance of cultured female Coho salmon in Chilli. Prog Fish Cult. 1997, 59, 36-40.

[7] F. Winkler, D. Bartley, N. Díaz: Genetic differences among year classes in a hatchery population of Coho salmon (Oncorhynchus kisutch) in Chilli. Aquaculture 1999, 173, 425-433.

[8] N. Romero, P. Robert, L. Masson, R. Pineda: Fatty acid composition and proximate of seven fish species of Eastern Island. Archivos Latinoamericanos de Nutrición 1996, 46, 75-77. 
[9] E. Gruger, R. Nelson, M. Stansby: Fatty acid composition of oils from 21 species of marine fish, freshwater fish and shellfish. J Amer Oil Chem Soc. 1964, 41, 662667.

[10] R. Braddock, L. Dugan: Fatty acids of lake Michigan Coho salmon. J Food Sci. 1969, 37, 426-429.

[11] J. Cheftel, H. Cheftel: Introducción a la Bioquímica y Tecnología de Alimentos. Editorial Acribia, Zaragoza (Spain) 1976, pp. 237-323.

[12] P. Harris, J. Tall: Rancidity in fish. In: Rancidity in foods. Eds. J. Allen, R. Hamilton, Chapman and Hall, London (UK) 1994, pp. 256-272.

[13] A. Kolakowska: Lipid oxidation in Food systems. In: Chemical and functional properties of food lipids. Eds. Z. Sikorski, A. Kolakowska, CRC Press, London (UK) 2003, 133-165.

[14] K. Hwang, J. Regenstein: Lipid hydrolysis and oxidation of mackerel (Scomber scombrus) mince. J Aquat Food Prod Technol. 1996, 5, 17-27.

[15] I. Undeland, G. Hall, H. Lingnert: Lipid oxidation in fillets of herring (Clupea harengus) during ice storage. J Agric Food Chem. 1999, 47, 524-532.

[16] E. Bligh, W. Dyer: A rapid method of total extraction and purification. Can J Biochem Physiol. 1959, 37, 911-917.

[17] R. Lowry, I. Tinsley: Rapid colorimetric determination of free fatty acids. J Am Oil Chem Soc. 1976, 53, 470-472.

[18] R. Kim, F. Labella: Comparison of analytical methods for monitoring autoxidation profiles of authentic lipids. J Lipid Res. 1987, 28, 1110-1117.

[19] R. Chapman, J. McKay: The estimation of peroxides in fats and oils by the ferric thiocyanate method. J Am Oil Chem Soc. 1949, 26, 360-363. 
[20] W. Vyncke: Direct determination of the thiobarbituric acid value in trichloracetic acid extracts of fish as a measure of oxidative rancidity. Fette Seifen Anstrichm. 1970, 72, 1084-1087.

[21] S. Aubourg, I. Medina, J. Gallardo: Quality assessment of blue whiting (Micromesistius poutassou) during chilled storage by monitoring lipid damages. J Agric Food Chem. 1998, 46, 3662-3666.

[22] S. Aubourg: Damage detection in horse mackerel (Trachurus trachurus) during chilled storage. J Am Oil Chem Soc. 2001, 78, 857-862.

[23] I. Hassan, M. Khallaf, L. Abd-El Fattah, N. Yasin: Quality criteria period and marketing loss estimations of pre-treated and cold stored mullet fish. Grasas y Aceites 1999, 50, 208-217.

[24] G. Lepage, C. Roy: Direct transesterification of all classes of lipids in a one step reaction. J Lipid Res. 1986, 27, 114-120.

[25] Z. Lubis, K. Buckle: Rancidity and lipid oxidation of dried-salted sardines. Int J Food Sci Technol. 1990, 25, 295-303.

[26] E. Sheehan, T. O’Connor, P. Sheehy, D. Buckley, R. Fitzgerald: Stability of astaxanthin and canthaxanthin in raw and smoked Atlantic salmon (Salmo salar) during frozen storage. Food Chem. 1998, 63, 313-317.

[27] P. Howgate: Codex review on inspection procedures for the sensory evaluation of fish and shellfish. CX/FFP 1992, 92/14.

[28] Statsoft: Statistica for Macintosh; Statsoft and its licensors, Tulsa, Oklahoma (USA) 1994.

[29] F. Pérez-Alonso, C. Arias, S. Aubourg: Lipid deterioration during chilled storage of Atlantic pomfret (Brama brama). Eur J Lipid Sci Technol. 2003, 105, 661667. 
[30] G. Piclet: Le poisson aliment. Composition et intérêt nutritionnel. Cah Nutr Diét. 1987, XXII, 317-335.

[31] M. L. Nunes, I. Batista, R. Morao de Campos: Physical, chemical and sensory analysis of sardine (Sardina pilchardus) stored in ice. J Sci Food Agric. 1992, 59, 37-43.

[32] A. de Koning: The free fatty acid content of fish oil, Part IV: Rates of free fatty acid formation from phospholipids and neutral lipids in anchovy (Engraulis capensis) stored at various temperatures. Fat Sci Technol. 1995, 97, 341-346.

[33] A. Pearson, J. Love, F. Shorland: Warmed-over flavor in meat, poultry and fish. Adv Food Res. 1977, 23, 2-61.

[34] M. Careche, R. García, J. Borderías: Anchovy shelf life as affected by different chilling methods during distribution. J Food Prot. 2002, 65, 353-361.

[35] J. Pokorný: Browning from lipid-protein interactions. Prog Food Nutr Sci. 1981, 5, 421-428.

[36] N. Howell: Interaction of proteins with small molecules. In: Ingredient Interactions- Effects on Food Quality. Ed. A. Gaonkar, Marcel Dekker, New York (USA) 1995, pp. 269-289.

[37] R. Iwamoto, J. Myers, W. Hershberger: Heritability and genetic correlations for flesh coloration in pen-reared Coho salmon. Aquaculture 1990, 86, 181-190.

[38] B. Bjerkeng, S. Refstie, K. Fjalestad, T. Storebakken, M. Rødbotten, A. Roem: Quality parameters of the flesh of Atlantic salmon (Salmo salar) as affected by dietary fat content and full-fat soybean meal as a partial substitute for fish meal in the diet. Aquaculture 1997, 157, 297-309. 
[39] J. Gordon Bell, J. McEvoy, J. Webster, F. McGhee, R. Millar, J. Sargent: Flesh lipid and carotenoid composition of Scottish farmed Atlantic salmon (Salmo salar). J Agric Food Chem. 1998, 46, 119-127.

[40] H. Refsgaard, P. Brockhoff, B. Jensen: Sensory and chemical changes in farmed Atlantic salmon (Salmo salar) during frozen storage. J Agric Food Chem. 1998, 46, 3473-3479.

[41] A. Christophersen, G. Bertelsen, H. Andersen, P. Knuthsen, L. Skibsted: Storage life of frozen salmonids. Effect of light and packaging conditions on carotenoid oxidation and lipid oxidation. Z Lebensm Unters Forsch. 1992, 194, 115-119.

[42] T. Ingemansson, A. Pettersson, P. Kaufmann: Lipid hydrolysis and oxidation related to astaxanthin content in light and dark muscle of frozen stored rainbow trout (Oncorhynchus mykiss). J Food Sci. 1993, 58, 513-518.

[43] C. Jensen, E. Birk, A. Jokumsen, L. Skibsted, G. Bertelsen: Effect of dietary levels of fat, $\alpha$-tocopherol and astaxanthin on colour and lipid oxidation during storage of frozen rainbow trout (Oncorhynchus mykiss) and during chill storage of smoked trout. Z Lebensm Unters Forsch. 1998, 207, 189-196.

[44] N. Krinsky: Antioxidant functions of carotenoids. Free Radical Biol Med. 1989, 7, 617-635.

[45] I. Gobantes, G. Choubert, R. Gómez: Quality of pigmented (astaxanthin and canthaxanthin) rainbow trout (Oncorhynchus mykiss) fillets stored under vacuum packaging during chilled storage. J Agric Food Chem. 1998, 46, 4358-4362.

[46] H. Andersen, G. Bertelsen, A. Christophersen, A. Ohlen, L. Skibsted: Development of rancidity in salmonoid steaks during retail display. A comparison of practical storage life of wild salmon and farmed rainbow trout. Z Lebensm Unters Forsch. 1990, 191, 119-122. 
[47] B. Pérez-Villarreal, R. Pozo: Chemical composition and ice spoilage of albacore (Thunnus alalunga). J Food Sci. 1990, 55, 678-682.

[48] K. Sveinsdottir, E. Martinsdottir, G. Hyldig, B. Jørgensen, K. Kristbergsson: Application of quality index method (QIM) scheme in shelf-life study of farmed Atlantic salmon (Salmo salar). J Food Sci. 2002, 67, 1570-1579.

[49] H. Refsgaard, P. Brockhoff, B. Jensen: Free polyunsaturated fatty acids cause taste deterioration of salmon during frozen storage. J Agric Food Chem. 2000, 48, $3280-3285$.

[50] H. Yoshida, I. Kondo, G. Kajimoto: Participation of free fatty acids in the oxidation of purified soybean oil during microwave heating. J Am Oil Chem Soc. 1992, 69, 1136-1140.

[51] S. Aubourg: Fluorescence study of the pro-oxidant effect of free fatty acids on marine lipids. J Sci Food Agric. 2001, 81, 385-390.

[52] A. Mortensen, L. Skibsted: Relative stability of carotenoid radical cations and homologue tocopheroxyl radicals. A real time kinetic study of antioxidant hierarchy. FEBS Lett. 1997, 417, 261-266. 


\section{FIGURE LEGENDS}

Figure 1: Free fatty acid formation* during Coho salmon chilled storage

* Bars denote standard deviations of the mean $(n=5)$.

Figure 2: Polyene index assessment* during Coho salmon chilled storage

* Bars denote standard deviations of the mean $(n=5)$.

Figure 3: Astaxanthin assessment* during Coho salmon chilled storage

* Bars denote standard deviations of the mean $(n=5)$.

Figure 4: Rancid odour detection* during Coho salmon chilled storage

* Bars denote standard deviations of the mean $(n=5)$. 


\section{TABLE 1}

Correlation values $(\mathrm{CV})^{*}$ between the chilled storage time and the different parameters analysed

\begin{tabular}{|c|c|}
\hline Parameter & $\mathbf{C V}$ \\
\hline Free fatty acids & $\mathbf{0 . 9 6}{ }^{\mathrm{a}}$ \\
\hline Conjugated dienes & $-0.17^{\mathrm{b}}$ \\
\hline Peroxide value & $\mathbf{0 . 9 6}{ }^{\mathrm{a}}$ \\
\hline $\begin{array}{c}\text { Thiobarbituric acid } \\
\text { index }\end{array}$ & $\mathbf{0 . 9 4}$ \\
\hline Fluorescence ratio \\
\hline Browning ratio & $\mathbf{0 . 7 9}$ \\
\hline Polyene index & $0.61^{\mathrm{c}}$ \\
\hline Astaxanthin content & $-0.45^{\mathrm{a}}$ \\
\hline $\begin{array}{c}\text { Rancid odour } \\
\text { development }\end{array}$ & $-\mathbf{0 . 8 1}^{\mathrm{c}}$ \\
\hline
\end{tabular}

* For each index, linear ${ }^{\mathrm{a}}$ quadratic $^{\mathrm{b}}$ and logarithmic ${ }^{\mathrm{c}}$ fittings were studied. In each case, the best correlation value is expressed. Significant values $(p<0.05)$ are written in bold print. 


\section{TABLE 2}

Assessment of lipid oxidation* during the chilled storage of Coho salmon**

\begin{tabular}{|c|c|c|c|c|c|}
\hline $\begin{array}{c}\text { Chilled } \\
\text { Time (days) }\end{array}$ & CD & PV & TBA-i & FR & BR \\
\hline 0 & $0.61 \mathrm{ab}$ & $1.17 \mathrm{a}$ & $0.02 \mathrm{a}$ & $0.13 \mathrm{c}$ & $8.83 \mathrm{a}$ \\
& $(0.08)$ & $(0.37)$ & $(0.02)$ & $(0.01)$ & $(2.85)$ \\
\hline 3 & $0.57 \mathrm{a}$ & $1.59 \mathrm{ab}$ & $0.05 \mathrm{a}$ & $0.10 \mathrm{abc}$ & $8.34 \mathrm{a}$ \\
$(0.04)$ & $(0.28)$ & $(0.06)$ & $(0.03)$ & $(1.20)$ \\
\hline 6 & $0.65 \mathrm{~b}$ & $2.32 \mathrm{bc}$ & $0.02 \mathrm{a}$ & $0.09 \mathrm{ab}$ & $10.00 \mathrm{a}$ \\
& $(0.07)$ & $(0.09)$ & $(0.03)$ & $(0.02)$ & $(2.16)$ \\
\hline 10 & $0.58 \mathrm{ab}$ & $2.35 \mathrm{c}$ & $0.05 \mathrm{a}$ & $0.06 \mathrm{a}$ & $8.94 \mathrm{a}$ \\
& $(0.03)$ & $(0.74)$ & $(0.04)$ & $(0.02)$ & $(1.18)$ \\
\hline 12 & $0.59 \mathrm{ab}$ & $2.50 \mathrm{~cd}$ & $0.07 \mathrm{a}$ & $0.06 \mathrm{a}$ & $10.30 \mathrm{a}$ \\
& $(0.07)$ & $(0.68)$ & $(0.04)$ & $(0.02)$ & $(2.21)$ \\
\hline 17 & $0.60 \mathrm{ab}$ & $2.69 \mathrm{~cd}$ & $0.07 \mathrm{a}$ & $0.11 \mathrm{bc}$ & $11.25 \mathrm{a}$ \\
& $(0.04)$ & $(0.53)$ & $(0.05)$ & $(0.04)$ & $(1.84)$ \\
\hline 19 & $0.61 \mathrm{ab}$ & $3.00 \mathrm{~cd}$ & $0.21 \mathrm{~b}$ & $0.12 \mathrm{c}$ & $10.31 \mathrm{a}$ \\
& $(0.03)$ & $(0.24)$ & $(0.08)$ & $(0.03)$ & $(2.06)$ \\
\hline 24 & $0.59 \mathrm{ab}$ & $3.80 \mathrm{~d}$ & $0.36 \mathrm{c}$ & $0.37 \mathrm{~d}$ & $9.53 \mathrm{a}$ \\
& $(0.03)$ & $(0.72)$ & $(0.17)$ & $(0.06)$ & $(2.95)$ \\
\hline
\end{tabular}

* Abbreviations: CD (conjugated dienes), PV (peroxide value), TBA-i (thiobarbituric acid index), FR (fluorescence ratio) and BR (browning ratio).

** In each column, mean values $(\mathrm{n}=5)$ followed by different letters are significantly $(\mathrm{p}<0.05)$ different. Standard deviations are indicated in brackets. 


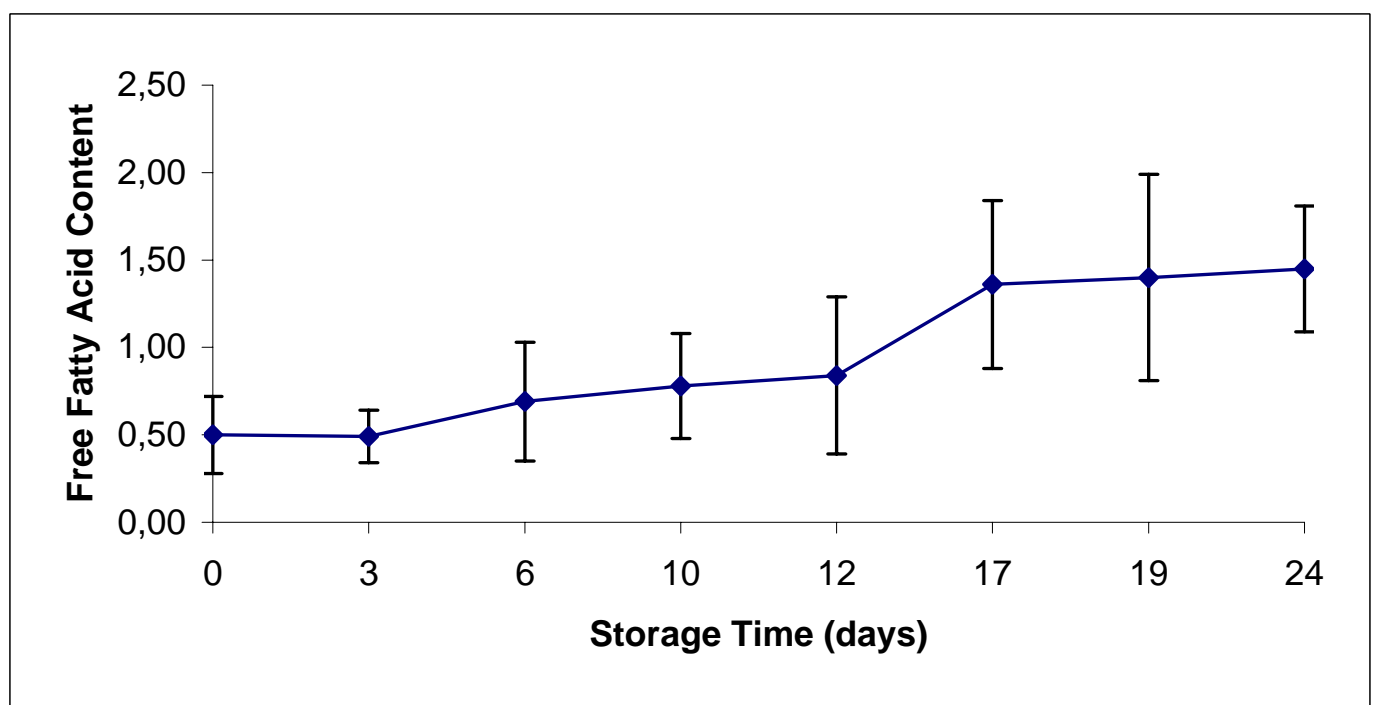




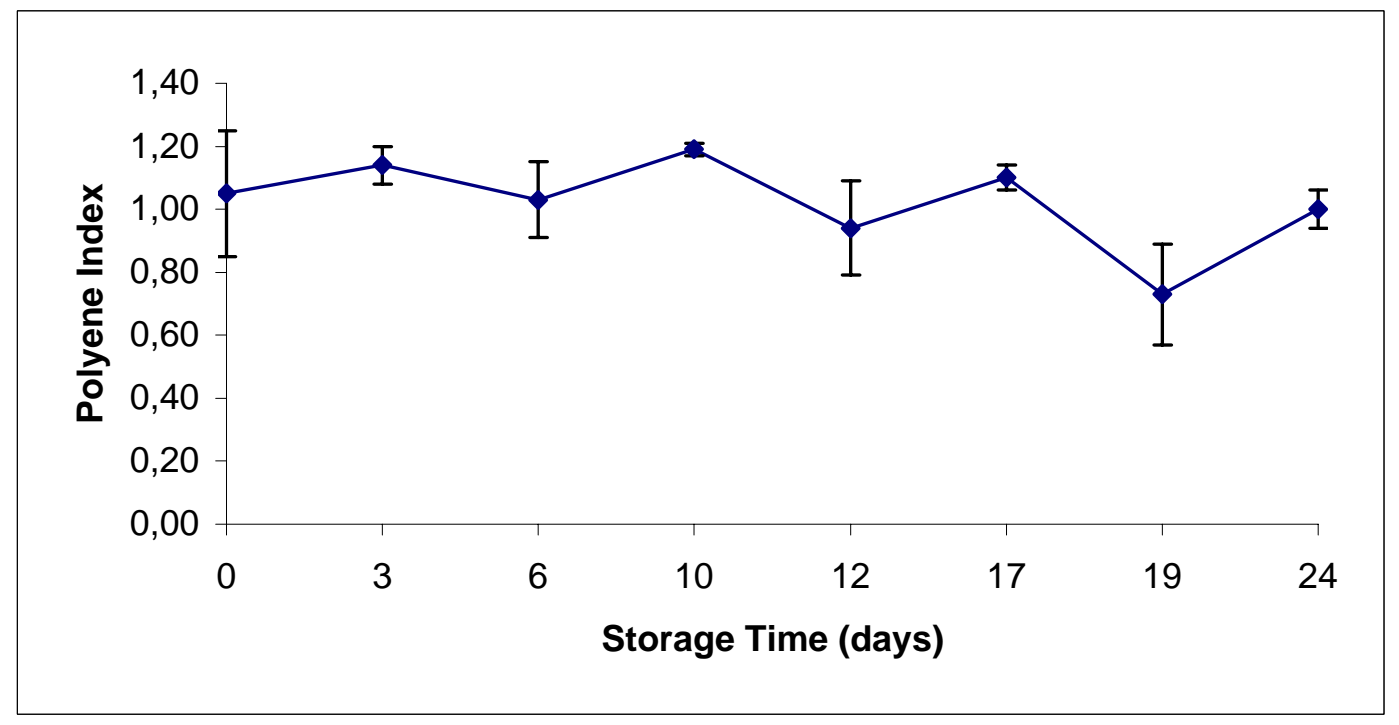




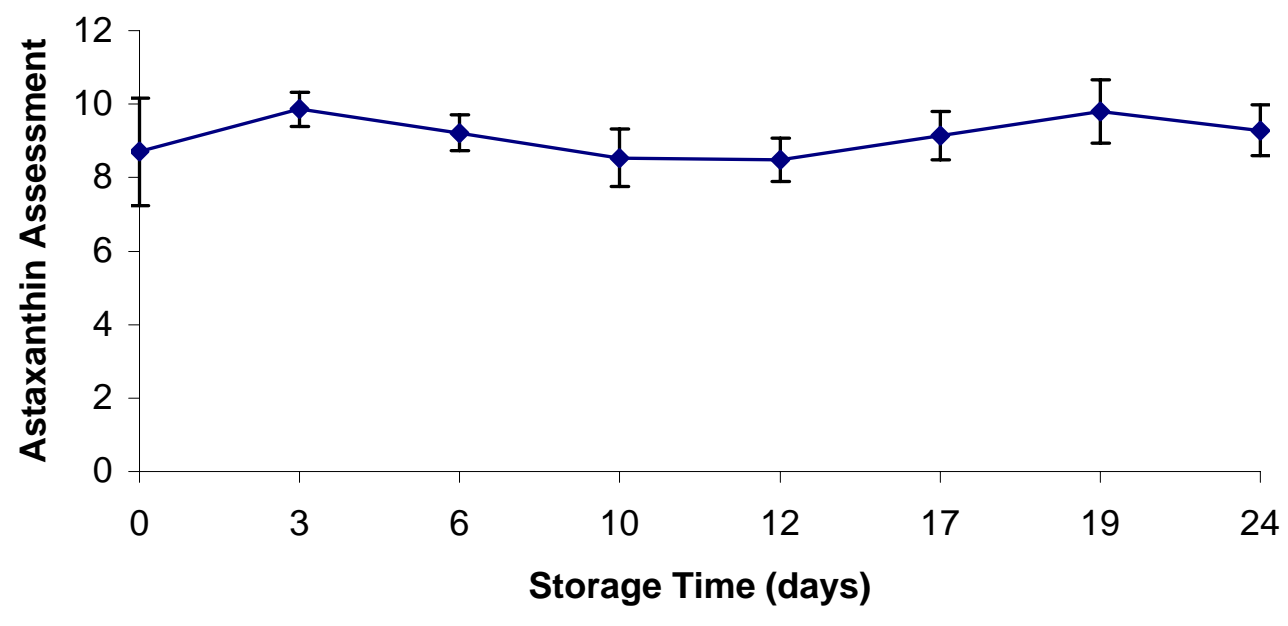




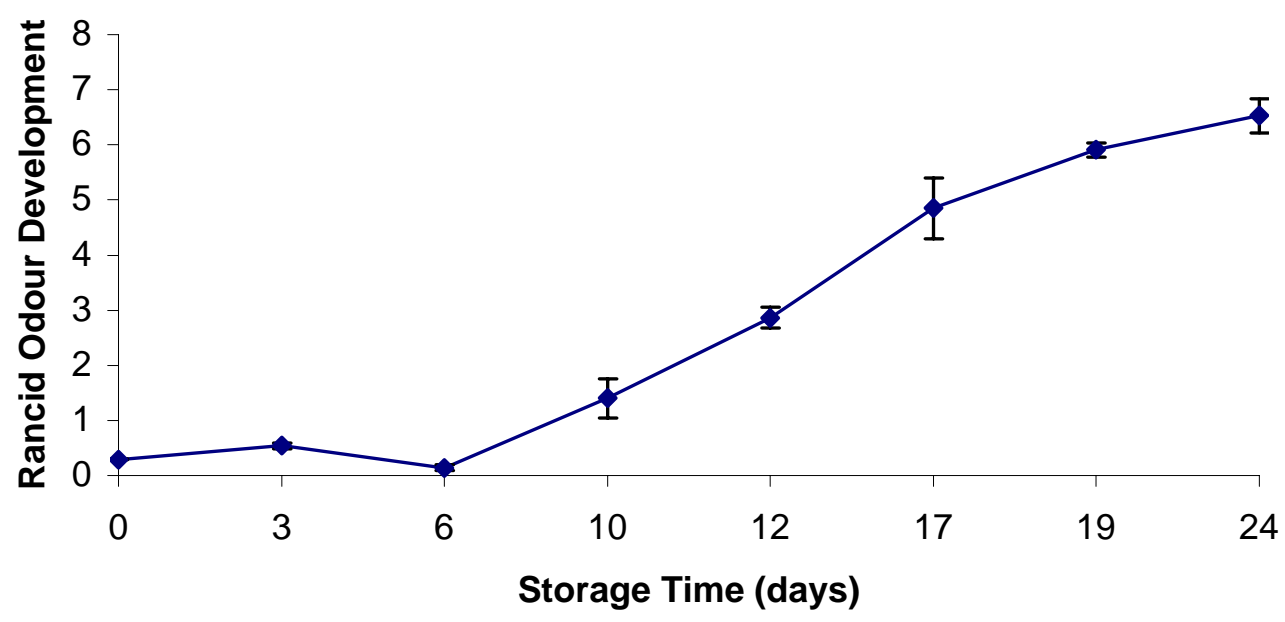

